\section{BIOPOLÍTICA NA ASSISTÊNCIA AOS USUÁRIOS DE ÁLCOOL E OUTRAS DROGAS}

\author{
Biopolitics in Assistance to Users of Alcohol and Other Drugs \\ Biopolítica en la Atención al Usuario de Alcohol y Otras \\ Drogas
}
Biopolitique à L'assistance aux Usagers D'alcool et D'autres Drogues

\section{Resumo}

Este artigo analisa as estratégias biopolíticas que operam na assistência à saúde das pessoas que fazem uso abusivo de álcool e outras drogas, tendo em vista os aspectos macro e micropolíticos do processo de trabalho em um Centro de Atenção Psicossocial Álcool e Drogas (CAPSad). Trata-se do resultado de pesquisa qualitativa realizada junto a todos os profissionais que atuavam naquele Centro, durante os meses de janeiro a agosto de 2014. Foram realizadas 80 horas de observação, entrevista coletiva com a participação de dez profissionais e 13 entrevistas em profundidade, seguidas da Análise Temática. Constatamos que, apesar da busca de desinstitucionalização dos serviços de saúde mental, há ainda práticas tutelares que persistem na "lógica manicomial", da qual querem se distanciar. Percebemos que há formas de captura biopolítica que sutilmente operam na assistência a esses usuários. Entre elas, destacamos a "higienização das ruas", o fortalecimento da dependência à instituição e a supremacia da burocracia em detrimento do cuidado. Assim, no que concerne ao aspecto macropolitico, é necessária a concretização de uma rede de atenção articulada, pois só assim se conseguirá junto ao usuário construir estratégias efetivas de autonomia, ou melhor, não dependência - tanto das substancias psicoativas e do álcool quanto de um serviço. Com relação ao aspecto micropolitico, a autonomia do usuário se dará por meio da realização de práticas de acolhimento-diálogo, a fim de que a permanência deste na instituição não seja mais necessária.

Palavras-chave: biopolítica; subjetividade; centro de atenção psicossocial; droga; diálogo.

\section{Abstract}

This article analyzes the biopolitics strategies operating in the health care of people who abuse alcohol and other drugs, in view of the macro and micro-political aspects of the work process in a Psychosocial Care Center Alcohol and Drugs (CAPSad). This is the result of a qualitative survey of all professionals working in this center from January to August 2014. 80 hours of observation and collective interviews were held, with the participation of 10 professionals and 13 in-depth interviews, followed by Thematic Analysis. We note that despite the pursuit of deinstitutionalization of mental health services, there are still tutelary practices that persist in "asylum logic", from which the distance is wanted. We realize that there are ways to capture biopolitics that subtly operate in assisting those users. Among them, we highlight the "cleaning the streets", the strengthening of dependence to the institution and the supremacy of bureaucracy at the expense of care. Thus, as regards the macro-political aspect, it is necessary the embodiment of a network coordinated attention, for only thus it will be achieved, with the user to build effective strategies of autonomy-or rather, no dependence - both of psychoactive substances and alcohol as a service. Regarding the micro-political

\section{Biopolítica e Subjetividades Contemporâneas}

\section{Kallen Wandekoken ${ }^{(1)}$ \\ Bruna Quintanilha ${ }^{(2)}$ \\ Maristela Dalbello-Araujo ${ }^{(3)}$}

1) Doutora em Saúde Coletiva pela Universidade Federal do Espírito Santo UFES. Professora Ajunta do Departamento de Enfermagem da UFES..

2) Doutoranda em Psicologia pela UFES.

3) Pós-Doutorada pelo Instituto de Medicina Social da UERJ. Professora associada da UFES no Programa de Pósgraduação em Saúde Coletiva. 
aspect, the user autonomy will be through the completion of the host dialogue practices in order his stay in the institution is no longer needed.

Keywords: biopolitics; subjectivity; psychosocial care centers; drug; dialogue.

\section{Resumen}

Este artículo evalúa las estrategias biopoliticas que operan en la atención a la salud de las personas que consumen alcohol $y$ otras drogas abusivamente, teniendo en vista los aspectos macro y micro políticos del proceso de trabajo en un Centro de Atención Psicosocial Alcohol y Drogas (CAPSad). Se refiere al resultado de una investigación cualitativa realizada junto con todos los profesionales que trabajaban en este Centro, entre los meses de enero y agosto de 2014. Fueron realizadas 80 horas de observación y entrevistas con participación de 10 profesionales y 13 entrevistas en profundidad, continuadas de Análisis Temático. Comprobamos que, mismo con la búsqueda por rotura de los servicios de salud mental en centros, aún hay practicas tutelares que siguen en la "lógica manicomial", de la cual se quieren distanciar. Percibimos que hay formas de captura biopolitica que sutilmente operan en la atención a estos usuarios. Entre ellas, resaltamos la "higienización de calles", el fortalecimiento de la dependencia a la institución y la supremacía de la burocracia en detrimento del cuidado. Así, a lo que se refiere al aspecto macro político, es necesaria la concretización de una red de atención articulada, porque solamente así se conseguirá, junto al usuario, construir estrategias efectivas de autonomía - es decir, no dependencia - tanto de la sustancias psicoactivas y del alcohol cuanto de un servicio. Con relación al aspecto micro político, la autonomía del usuario será por la realización de prácticas de acogida-dialogo, con el fin de que su permanencia en la institución ya no sea necesaria.

Palabras clave: biopolitica; subjetividad; centros de atención psicosocial; droga; diálogo.

\section{Résumé}

Cet article analyse les stratégies biopolitiques presentes à l'assistance à la santé des personnes qui abusent de l'alcool et d'autres drogues en visant les aspects macro et micropolitiques du processus de travail à un Centre d'Attention Psychossocial Alcool et Drogues (CAPSad). C'est le résultat d'une recherche qualitative réalisée avec touts les professionnels qui travaillent à ce Centre pendant les mois de janvier jusqu'à août de 2014. On a fait 80 heures d'observation et interview colective avec 10 professionnels et 13 interviews en profondité. suivies de l'Analyse Thématique. On a constaté que malgré la recherche de la désinstitutionnalisation des services de santé mentale, il y a encore des pratiques tutélaires qui persistent dans la "logique de l'hôpital psychiatrique » dont ils veulent se distancer. On a remarqué qu'il y a des manières de saisissement biopolitique qui opèrent subtilement dans l'assistance à ces usagers. D'entre ces manières-là, on détache " la désinfection des rues ", la fortification de la dépendence de l'intitution, la suprematie de la bureaucratie sur le soingnement. Ansi, à ce qui concerne à l'apect macropolitique, il faut la concrétisation d'un réseau d'attention articulée, car c'est la seule manière de rendre possible la réalisation des stratégies efficaces d'autonomie pour les usagers - ou plutôt, de non dépendance - tant des substances psychotropes et de l'alcool comme des services d'assistance. En relation à l'aspect micropolitique, l'autonomie de l'usager se fera au moyen de la réalisations des pratiques d'accueil et dialogue à fin d'il n'avoir plus besoin de rester à l'institution.

Mots-clés: biopolitique; subjectivité; Centre d'Attention Psychossocial; drogue; dialogue.

Os Centros de Atenção Psicossocial Álcool e Drogas (CAPSad) são serviços de fundamental importância na assistência ao usuário que faz uso abusivo de substâncias psicoativas. Para que esse serviço consiga cumprir com as diretrizes do Ministério da Saúde e prestar uma assistência que prime pela produção do cuidado e de autonomia aos usuários, é preciso compreender quais práticas estão se produzindo a partir das relações estabelecidas entre os profissionais e destes com os usuários. Desse modo, entendemos ser fundamental discutir como as relações micro e macropolíticas têm emergido no cotidiano de um CAPSad.

Nos espaços institucionais, para Deleuze e Guattari (1996), “tudo é político", desde que não se considere política apenas a dimensão macropolítica, mas também aquela que se expressa nas tensões e afetos, ou seja, na micropolítica. Assim, diferente de outras concepções a respeito da política, os autores nos propõem refletir a respeito de uma ligação estreita entre as referidas dimensões.

É fundamental enfatizar que "macro" e "micro" não se relacionam com grande e pequeno, nem com a oposição entre Estado ou sociedade e grupos pequenos. Deleuze e Guattari (1996) consideram que a diferença entre as duas dimensões se refere ao modo de funcionamento, assim, a macropolítica consiste em sobrecodificar, segmentar o movimento da vida, e a micropolítica atua para fluir, criar. Além disso, os autores afirmam que a primeira possui organização visível e administra a vida de forma instituída, e a segunda possui organização invisível e pode tanto oprimir quanto pode inventar novas conexões. Assim, as dimensões apresentam relações bem distintas, pois a primeira coloca em jogo "conjuntos ou elementos bem determinados (as classes sociais, os homens, determinadas pessoas)" e a segunda se refere "aos fluxos e partículas que escapam dessas classes, desses sexos, dessas pessoas" (Deleuze \& Guattari, 1996, p. 68).

A macropolítica, então, refere-se a uma "linha de 
segmentaridade dura", de forma que "tudo parece contável e previsto, o início e o fim de um segmento, a passagem de um segmento a outro". Já a micropolítica se refere a uma "linha de segmentação maleável" que "não é simplesmente interior ou pessoal" (Deleuze \& Guattari, 1996, pp. 67-72). Elementos de cunho macropolítico são, por exemplo, a dificuldade de gestão dos poderes locais, as divergências políticas entre o nível federal e o municipal, entre outros. Os aspectos micropolíticos se referem às dificuldades vivenciadas pelos trabalhadores no cotidiano, nas relações. Assim, um Centro de Atenção Psicossocial Álcool e Drogas (CAPSad), por exemplo, se constitui na articulação da dimensão macropolítica, que determina as normas de funcionamento e de administração, com a dimensão micropolítica, que se compõe no modo como os sujeitos (trabalhadores, usuários e famílias) se tensionam entre assujeitamentos e conexões, no exercício singular de cada equipe.

É importante frisar que a diferença entre macro e micropolítica não está entre o plano individual e o coletivo. Deleuze e Guatarri (1996) afirmam que a macropolítica se constitui no regime molar, que diz respeito à organização e funcionamento das instituições, já a micropolítica se relaciona com o plano molecular, uma vez que diz respeito aos fluxos e processos, ou seja, a nós e nossas relações. Assim, não só toda sociedade, mas todos os indivíduos são atravessados tanto pelo plano molar como pelo plano molecular (Deleuze \& Guattari, 1996).

Isto é, as dimensões se distinguem, coexistem e são inseparáveis. Não pretendemos negar a importância da dimensão macropolítica, mas afirmar a potência da dimensão micropolítica. Logo, constatamos que a macropolítica é essencial à micropolítica, de forma que aquela é a sobrecodificação dos fluxos desta; e na mesma medida, a micropolítica é essencial à macropolítica, inclusive, se a desconsiderarmos, corremos o risco de não perceber os fluxos que podem tanto fortalecer quanto enfraquecer esta última.

Assim, para Deleuze e Guattari (1996):

[...] se consideramos os grandes conjuntos binários, como os sexos ou as classes, vemos efetivamente que eles ocorrem também nos agenciamentos moleculares de outra natureza e que há uma dupla dependência recíproca, pois os dois sexos remetem a múltiplas combinações moleculares, que põem em jogo não só o homem na mulher e a mulher no homem, mas a relação de cada um no outro com o animal, a planta, etc.: mil pequenos-sexos. (Deleuze \& Guattari, 1996, p. 83)

Nesse caso, Deleuze e Guattari (1996) explicitam que as organizações e funções que compõem a sociedade, em nível molar, só podem existir porque há a ação de processos materiais menos visíveis, como são os afetos, as crenças, os sentimentos, os modos de pensar, os desejos, entre outros.

$\mathrm{Na}$ dimensão macropolítica, devemos, então, relembrar a organização e normatização dos serviços nas leis e decretos, bem como de problemáticas relativas ao trabalho em saúde enfrentadas pelas diferentes esferas do governo. Nesse sentido, Franco e Merhy (2006) apontam que os serviços de saúde, em sua maioria, funcionam conforme o modelo hegemônico, determinado a partir de questões relacionadas à macroestrutura social, à divisão técnica e social do trabalho, bem como aos aspectos da política de saúde e de ordem mercadológica. Merhy (2002) afirma, ainda, que os aspectos macropolíticos definem em grande medida a estrutura e a organização dos serviços.

Corroborando com essas ideias, Zambenedetti (2009) afirma que a macropolítica deve ser entendida a partir das questões normativas, englobando os modelos e métodos organizacionais. Nesse sentido, Merhy (1999) acredita que há jogos de forças entre o instituído e o instituinte, ou seja, entre aquilo que está posto e as possibilidades de criação, frente às novas configurações, de modo que a forma de organizar a gestão em saúde não pode ser baseada apenas em modelos clássicos administrativos.

Neswe contexto, Zambenedetti (2009) considera, ainda, que as questões macropolíticas incluem também um fator subjetivo, o que demonstra o grau de autonomia do trabalho em saúde, já explicitado por Merhy (2002), e exemplifica a atualização das diretrizes macropolíticas da rede de saúde mental que, de fato, abrangem o fator subjetivo relacionado à implicação do trabalhador com as diretrizes do processo de trabalho.

Segundo Merhy (2002), as definições macropolíticas implicam, desse modo, a organização dos processos de trabalho em saúde, mas são colocadas em análise a partir da experiência micropolítica em ato, até porque entendemos que grupos não hegemônicos também produzem em suas práticas políticas. Dessa forma, Franco e Merhy (2006) apontam que os aspectos relacionados à micropolítica da organização dos serviços também dizem respeito às relações que são firmadas no processo de trabalho, bem como aos interesses em jogo no cotidiano dos serviços.

Franco (2009) menciona que, para se compreender a micropolítica do processo de trabalho em saúde, é preciso entender o modo como se produz o cuidado, considerando as interfaces de saberes e poderes, as intersubjetividades e, ainda, o desvendar de aspectos do "encontro mágico entre os trabalhadores de saúde e os usuários". Compreendemos, nesse sentido, que o trabalho em saúde se realiza a partir das relações que se caracterizam por tensões e embates entre necessidades e interesses.

A fim de analisar os aspectos macro e micropolíticos de um CAPSad, as contribuições de Michel Foucault sobre biopolítica (práticas sociais que se exercem sobre os corpos e as populações) e biopoder (vida submetida ao poder da política) colocam-se necessárias na produção de reflexões. 
Para Foucault, não existe o Poder, mas relações de poder, ou seja, "formas díspares, heterogêneas, em constante transformação. O poder não é um objeto natural, uma coisa; é uma prática social e, como tal, constituída historicamente" (Machado, 1979, p. XXI). Já o conceito de biopolítica surgiu em uma palestra ministrada por Foucault, em 1974, intitulada "O nascimento da medicina social", na qual ele afirma que "o corpo é uma realidade biopolítica" e "a medicina é uma estratégia biopolítica" (Foucault, 1979, p. 80). O autor aponta um deslocamento nas estratégias de poder:

[...] o controle da sociedade sobre os indivíduos não se opera simplesmente pela consciência ou pela ideologia, mas começa no corpo, com o corpo. Foi no biológico, no somático, no corporal que, antes de tudo, investiu a sociedade capitalista. O corpo é uma realidade biopolítica. (Foucault, 1979, p. 82)

Para Foucault (1979), um poder que tem a tarefa de garantir a vida, terá sempre como consequência a instauração de normas. Segundo o autor "uma sociedade normalizadora é o efeito histórico de uma tecnologia de poder centrada na vida" (Foucault, 1979). Desta forma, a vida, o corpo, a saúde, as necessidades, a reprodução, transformam-se em questões políticas por excelência.

[...] é cada vez menos o direito de fazer morrer e cada vez mais o direito de intervir para fazer viver, e na maneira de viver, e no "como" da vida, a partir do momento em que, portanto, o poder intervém, sobretudo nesse nível para aumentar a vida, para controlar seus acidentes, suas eventualidades, suas deficiências, daí por diante a morte, como termo da vida, é evidentemente o termo, o limite, a extremidade do poder. (Foucault, 1997, p. 221)

A biopolítica, portanto, revela-se um dispositivo que regulamenta a vida, já não mais voltada para o indivíduo, mas à população em sua natureza biológica de conjunto e se configura por um conjunto de técnicas (biopoder) capazes de interferir diretamente nos destinos da vida humana (Foucault, 1998, p. 134). Ressaltamos que, para Foucault (2008), população não se refere a um conjunto de indivíduos, mas sim o resultado de um conjunto de variáveis, representada pelos valores morais, religiosos, etc.

Neste contexto, ao refletir sobre o que as dimensões macro e micropolíticas e sobre a biopolítica, questionamos tais aspectos presentes no CAPSad. Com base nessas questões, este artigo analisa as estratégias biopolíticas que operam na assistência aos usuários de álcool e outras drogas, tendo em vista os aspectos macro e micropolíticos do processo de trabalho em um Centro de Atenção Psicossocial Álcool e Drogas.

\section{Método}

Foi realizada uma pesquisa qualitativa em um CAPSad, sendo incluídos todos os 28 profissionais que atuam nessa instituição, desde os que possuem formação específica em cursos da área da saúde até os que prestam outros serviços. Desse modo, foram convidados a participar da pesquisa: médicos, enfermeiros, psicólogos, assistentes administrativos, motoristas, recepcionistas, vigilantes, auxiliares de serviços gerais, farmacêuticos, educadores físicos, terapeutas ocupacionais, gerentes, técnicos de enfermagem e assistentes sociais.

É importante ressaltar que entendemos por trabalhadores de saúde todos aqueles que, de alguma forma, intervêm na cadeia produtiva do cuidado. e não só os que possuem conhecimentos técnicos em questões de saúde. Por isso, todos, independentemente de sua formação ou função, foram convidados a participar da pesquisa, de forma que não faremos tal identificação na apresentação dos resultados, pois acreditamos que todos estão atravessados pelas tensões, emoções, ansiedades e desejos. Assim, consideramos o serviço como um todo.

O campo da pesquisa foi realizado entre os meses de janeiro a abril de 2014. Os dados foram produzidos por meio de entrevista coletiva com 10 trabalhadores a partir de um fluxograma prévio do processo de trabalho, que funcionou como dispositivo interrogador e por meio de roteiro semiestruturado, com os seguintes temas: trabalho no CAPSad, relação entre profissionais, com os usuários e com a rede, práticas terapêuticas e dificuldades encontradas para realizar o trabalho. Também foram feitas 13 entrevistas em profundidade, com a questão "o que você acha de trabalhar aqui?", a fim de apreender a lógica do serviço, pois são eles quem detém a história de seu processo de trabalho e deste modo, também são eles que vivenciam os efeitos produzidos. Realizamos 80 horas de observação do cotidiano e das reuniões de equipe a fim de perceber comportamentos de interação e, dessa forma, explorar questões que não surgiram facilmente nas entrevistas.

Todos os dados foram anotados e transcritos em um diário de campo, em que foi realizada a Análise Temática, derivada da Análise de Conteúdo, desenvolvida por Bardin (2009). É importante esclarecer que a Análise Temática está ligada à noção de tema, que pode ser graficamente apresentado por meio de uma palavra, uma frase ou um resumo. "O tema é a unidade de significação que se liberta naturalmente de um texto analisado segundo critérios relativos à teoria que serve de guia à leitura" (Bardin, 2009, p.131).

Foram atendidas todas as prerrogativas da Resolução n ${ }^{\circ} 466 / 12$ do Conselho Nacional de Saúde, sendo a pesquisa aprovada sob o número de registro n. 16771113000005060 pelo Comitê de Ética em Pesquisa da Universidade Federal do Espírito Santo. 


\section{Resultados e Discussão}

Destacamos neste CAPSad: condições de trabalho precárias (devido à estrutura do serviço, baixos salários e rede de atenção inexistente), sobrecarga (devido a falta de profissionais e devido aos conflitos nas divisões de tarefas) e falta de reconhecimento (devido à omissão da gerência e à ausência de normas).

Para análise e discussão dos resultados, criamos três categorias para apresentar as diferentes estratégias biopolíticas que operam na assistência aos usuários de álcool e de outras drogas: 1) "higienização das ruas"; 2) fortalecimento da dependência à instituição; 3) supremacia da burocracia em detrimento do cuidado. Ressaltamos que, apesar de o tema "medicalização dos sintomas" estar em evidência quando se trata de biopolítica, em decorrência da tamanha omissão presenciada nesta pesquisa, essa estratégia não foi identificada.

\section{"Higienização das Ruas"}

Pudemos vivenciar junto aos trabalhadores do CAPSad algumas estratégias operadas pela prefeitura da cidade, voltadas para a repressão do uso de álcool e outras drogas. Entre as estratégias, uma que destacamos foi a ação para retirada dos moradores de rua, devido à repercussão de uma reportagem de um jornal local, afirmando que eles estavam prejudicando a beleza da pracinha do centro do município. Podemos constatar alguns detalhes da ação no diário de campo e no depoimento do trabalhador:

Quando chegamos lá, havia duas caçambas grandes e um carro-pipa. O trabalhador explicou que as caçambas seriam para jogar fora os pertences dos moradores de rua e que o carro pipa é para jogar água no local, evitando assim que eles retornem. Disse que a ação durará até sexta-feira e que acontecerá na parte da manhã e da tarde. Havia policiais, pessoas que atuam na abordagem de rua, vários guardas municipais, e apenas três pessoas em situação de rua. (Diário de campo)

É melhor ficarmos de longe, para que os moradores não nos vejam e associem o CAPSad a essas abordagens. Acreditamos que essas abordagens são contrárias ao que fazemos, e mesmo que a prefeitura tenha pedido a parceria do CAPSad, nós não aceitamos. Só fomos antes para incentivar os moradores de rua a irem ao CAPSad antes da abordagem. Estive ontem na reunião no gabinete do prefeito e lá disseram que esta ação é para dar uma resposta à reportagem que foi veiculada na mídia alguns dias atrás, sobre os moradores de rua na pracinha. Eles usaram palavras como "higienização das ruas"; disseram que era para retirar os moradores, ameaçá-los e expulsálos. (Trabalhador)
De acordo com os trabalhadores, a abordagem às pessoas que estão em situação de rua deve ser vista como "higienização". Para eles, essas ações não podem ser consideradas estratégias que promovam alguma atenção ou cuidado a esses indivíduos; pelo contrário, são estratégias que excluem de forma perversa ao ameaçar, expulsar e jogar água, com a intenção de tornar o município mais belo.

Nesse sentido, Varanda e Adorno (2004) afirmam que os programas sociais, muitas vezes, expressam a ideologia do descarte social de uma população que é vista como excedente - são os descartáveis urbanos. São programas marcados pela retirada dessas pessoas da rua, mas que oferecem poucas possibilidades de reestruturação. Segundo os autores, "o recolhimento do lixo urbano e a 'remoção' de pessoas para espaços 'coletivos' de serviços assistenciais, que comportam centenas de pessoas, são ações muito próximas, ainda que executadas por profissionais de diferentes secretarias" (Varanda \& Adorno, 2004, p. 67).

É possível pensar essas estratégias de "higienização das ruas" como uma forma de captura de biopolítica. Segundo Foucault (1997), para que a biopolítica exerça uma relação positiva com a vida, de modo a aumentar a força das populações, a sociedade aceita vivenciar (de forma explícita ou implícita) processos de exclusão de tudo o que lhe pareça uma ameaça - são estratégias que regulam por meio da exclusão.

Uma dessas estratégias é o racismo, para Foucault (1997), não limitado à exclusão das raças, mas relacionado a uma hierarquização biológica em que são promovidas a exclusão e até a aversão entre as populações. Nesse sentido, o autor menciona que os direitos de "fazer morrer" e "deixar viver" do soberano foram substituídos, nos séculos XVIII e XIX, pelos poderes de "fazer viver" e "deixar morrer".

Entendemos, assim, que o objetivo da biopolítica será, de um lado, maximizar as forças da população e, de outro, produzir o "esquecimento" dos indivíduos que já estão às margens e apresentam vulnerabilidades, de modo que os não marginalizados simplesmente os ignoram ou os "deixam morrer".

Nesse contexto, destacamos o que um trabalhador mencionou:

O município faz o que eu chamo de 'tocagem', eles tocam os usuários de lá... Eles vão com polícia, delegado, o pessoal da abordagem de rua e tiram todos os usuários [...]. Teve uma vez que eles pediram apoio do CAPSad e fomos lá, mas ficamos de longe. Vimos que eles pegaram um caminhão e foram empurrando e retirando as casas e coisas dos usuários.. Assim é complicado. Ninguém aqui concorda, porque CAPSad tem outra lógica, e é difícil porque o usuário um dia vê que somos 'amigos', somos da saúde, e no outro vê a gente junto com a polícia, retirando eles dali. Então, nós não participamos dessa 
atividade [...]. Nas reuniões do gabinete, eles dizem mesmo que irão retirar tudo o que for dos usuários, que vão limpar as ruas e que irão lavar o lugar onde eles ficam, ou que vão plantar plantas com espinhos onde eles ficam. (Trabalhador)

A fala nos remete a um processo de "higienização" da cidade. Foucault (1979) aponta que uma das funções da medicina na Europa no século XIX, foi esquadrinhar a cidade e separar pobres de ricos. Isso porque os médicos e químicos da referida época, inferiram que as epidemias eram geradas pelos hábitos de vida e higiene da camada pobre da sociedade, logo, era preciso um controle rígido da vida destes para garantir que as doenças não se espalhassem. O mesmo autor aponta que a partir dessa premissa iniciouse um processo de controle do outro, o que fez com que se normatizassem todos os aspectos da vida dos que eram pobres, inclusive seus desejos.

Ainda de acordo com Foucault (1979), a camada pobre da sociedade aparece como uma ameaça urbana a partir do século XIX, pois começou a participar de revoltas e se tornou uma força política capaz de insurgir contra as camadas mais ricas (Foucault, 1979). A partir desses fenômenos, a camada mais pobre da sociedade passou a ser vista como uma ameaça por aqueles que hierarquicamente detém poder, logo, ela deveria ser afastada dos centros comerciais urbanos, vigiada e controlada para que deixe de ser uma ameaça.

A partir da fala dos trabalhadores do CAPSad pesquisado, notamos que ideia de higienização da cidade, tal como dissertada por Foucault (1979), permanece presente na conformação da sociedade atual. Ainda se entende o pobre - no caso, o morador de rua - como uma ameaça social, por isso, deve ser afastado dos locais nobres da cidade. Na verdade, melhor seria se eles não existissem, deste modo, constroem-se ações para 'deixar morrer' os que ameaçam a população "saudável e forte".

\section{Fortalecimento da Dependência à Instituição}

Discutindo ainda com enfoque nos aspectos macropolíticos, seguimos para a análise da rede de atenção. Ao questionar sobre o que acha de trabalhar na instituição um trabalhador disse:

Não é fácil e às vezes é chato, porque não tem uma rede externa de apoio, e sem essa rede não tem como o usuário ter uma melhora. [...] Como no município não tem uma rede externa, o paciente fica sendo atendido no CAPSad e fica nos abrigos, mas quando sai, não tem o suporte que precisa, não tem emprego, não tem onde ficar e acaba voltando ao uso de drogas. E aí, volta para o CAPSad, o que acaba gerando um ciclo. Ou seja, o paciente fica dependente do CAPSad. Alguns usuários, muitas vezes, chegam a ficar seis meses ali na atenção diária. (Trabalhador)

O trabalhador afirma que, devido à inexistência da rede de atenção psicossocial, o usuário fica dependente do serviço, criando um ciclo vicioso que desqualifica o serviço e o usuário que sente que nada adianta. Assim, questionamos como um serviço que se propõe a atuar na busca da autonomia dos usuários, frente à dependência química pode estar favorecendo a dependência ao serviço? Há interesse real na reabilitação e reinserção social desses usuários? Como vemos, essas estratégias (ou melhor, a falta delas) são uma manifestação da lógica de "deixar morrer", própria da biopolítica proposta por Foucault.

É notório ressaltar que essas estratégias coexistem com o processo de desinstitucionalização ou "desmanicomialização" da loucura, que está em andamento desde a Reforma Psiquiátrica, na década de 1970, e mais ainda com a lei $\mathrm{n}^{\circ} 10.216 / 2001$ (Lei no 10.216/2001, 2001). Destacamos que Reforma Psiquiátrica prevê a substituição dos dispositivos asilares, com o objetivo de que ocorra reinserção social, de modo a promover a articulação dos usuários aos serviços em seu contexto social, conforme prevê a Política de Atenção Integral aos Usuários de Álcool e outras Drogas - PAIUAD (Ministério da Saúde, 2003).

Frente à falta de uma rede de atenção articulada que favoreça a reinserção social e a reabilitação psicossocial dos usuários, questionamos: Em quê o ciclo de dependência ao serviço se diferencia da lógica manicomial? A clausura manicomial deixava claro que o indivíduo ficaria longe do convívio social, diminuindo seus vínculos afetivos e causando a dependência aos procedimentos tutelares (Amarante, 1996). Entretanto, no CAPSad, apesar de esperarmos uma mudança na vida cotidiana dos usuários, observa-se que há uma grande aproximação da lógica manicomial, como se esse serviço existisse, mas não realizasse aquilo a que se propõe.

Para entendermos melhor como se dá esse processo, enfocamos os aspectos que parecem confirmar que "não foi feito para funcionar":

O posto de enfermagem está lá, mas não tem ambulância, não tem motorista. Geralmente a gente dá carona para o PA [pronto atendimento]! Despacha ele lá!. “O negócio é se livrar da pessoa que passa mal! (risos). Põe o paciente na kombi se o SAMU não vem; dá uma carona ao PA ou ao HEAC [Hospital Estadual de Atenção Clínica]. (Trabalhadores em roda)

A falta de recurso parece denunciar a tentativa de não querer ver ou vivenciar situações em que ele é necessário. Dizeres como: “despacha ele lá”, "o negócio é se livrar da pessoa" ou ainda "mandam para o PA" denunciam a ausência de cuidado e de afeto que deveria haver nas 
relações em um serviço de saúde. Entendemos que essas falas apontam para a estratégia biopolitica e manifestação da lógica do "deixar morrer". Isso porque, em vez de se criarem estratégias que potencializem o usuário, para que este consiga construir outros modos de relação com o mundo e, com isso, ressignificar sua relação com a droga, opta-se pelo afastamento dele. Assim, o objetivo de estabelecer laços de afetos, ou seja, produzir potência de vida, passa a ser o de não criar vínculos, logo, "deixar morrer".

Outros trabalhadores relatam o seguinte:

O CAPSad é figurativo, só serve para arrecadar dinheiro. (Trabalhador)

Pensa em uma torneira, feito aquela torneira ali, olha. Vamos pensar que ela está aberta constantemente. O serviço no CAPSad é como enxugar a água dessa torneira que não para de cair água. Ou seja, é impossível! Trabalhar aqui é muito desestimulante, porque não tem recursos, e isso desanima muito. Não tem carro, não tem instrumentos nem equipamentos para trabalhar. Como você vai trabalhar com reabilitação psicossocial dessa forma? Não tem como! (Trabalhador)

Frente a essas falas, cabe questionar: há interesse para o cuidado desses usuários? Chama atenção o fato de um trabalhador dizer que a instituição é figurativa e que é impossível trabalhar, pois nada é solucionado e o objetivo principal do CAPSad, ou seja a reabilitação psicossocial, não é atingido. Soma-se a essas falas o que os trabalhadores mencionaram na entrevista coletiva:

Eles vêm aqui só pra comer. Tem um paciente que está na atenção diária há seis anos! Está institucionalizado! (Trabalhadores em roda)

Ressaltamos que a atenção diária mencionada pelos trabalhadores se refere às atividades desenvolvidas em um cuidado considerado intensivo (por ser realizado todos os dias da semana, tanto pela manhã como pela tarde), destinado aos usuários com maiores problemas relacionados ao uso de álcool e outras drogas. Observamos que há usuários que frequentam a instituição há seis anos, todos os dias, sem uma nova avaliação sequer.

Assim, constatamos que, apesar de se lutar pela desinstitucionalização dos serviços de saúde mental, há ainda práticas tutelares próprias da "lógica manicomial" da qual se quer distanciar, uma vez que há formas de captura biopolítica que sutilmente mantém essa lógica. Entendemos que se por um lado essas práticas podem ser necessárias, corre-se o risco de que elas se tornem cronificadas, reproduzindo a lógica manicomial. Além disso, a fala enfatiza que as práticas assistenciais no CAPSad em questão visam ao controle e apaziguamento dos usuários, ou seja, são estratégias biopolíticas, tendo em vista a lógica de descartar o que não se enquadra, fazendo isso por meio de equipamento de saúde, ou seja, por meio do biopoder (Foucault, 1979), o qual, mais uma vez, configura-se como uma forma de silenciar os indivíduos que fazem uso de álcool e outras drogas.

A questão que se coloca, então, é como operar para que o cuidado não se transforme em tutela? Acreditamos que um caminho seja a análise dos aspectos macro e micropolíticos que atravessam o cotidiano das relações entre usuários e profissionais de saúde.

\section{Supremacia da Burocracia em Detrimento do Cuidado}

No decorrer de nossas idas ao CAPSad, observamos que, na rotina diária dos usuários, há o controle do tempo em que lá estão, mas também fora. Controla-se, assim, o tempo do início e do término das atividades, o tempo em que o fumódromo pode ser usado, o tempo em que o usuário deve permanecer no serviço, o tempo disponível para as refeições etc.

Assim que o usuário é acolhido na instituição, há o estabelecimento do contrato terapêutico ${ }^{1}$. O documento deve ser assinado pelo usuário e suas diretrizes são fiscalizadas pelos profissionais, havendo punição no caso de desrespeito às normas - de uma advertência verbal até a suspensão do tratamento. Entre as normas, encontram-se: horário de chegada e de saída; horário das refeições e das atividades; necessidade de abstinência para a realização das atividades; horário e local em que é permitido o uso do cigarro, entre outras. Isso faz com que os usuários sejam controlados a todo o momento, até no que diz respeito à vida fora da instituição, como se constata na fala de um trabalhador:

Olha, outro dia eu dei suspensão pro paciente que saiu da atenção diária sem falar nada! (Trabalhador)

O enfoque em estratégias de controle do tempo e do espaço é mencionado por Foucault (2008) quando afirma que "a disciplina fabrica assim corpos submissos e exercitados, corpos “dóceis"”. Foucault (1979) menciona ainda que uma forte característica da sociedade atual é o investimento sobre o corpo: o que o corpo faz, como faz, como deve fazer, o que deve querer fazer, onde, em quanto tempo etc. Esse investimento sobre o corpo, que se relaciona com a disciplina, é também uma forma de captura biopolítica.

O controle do tempo e do espaço - considerados por nós dispositivos burocráticos - parece ir ao encontro da lógica manicomial, configurando uma forma diferente de controle da vida, que vai além do aprisionamento do corpo.

Entendemos, nesse ponto, que algumas práticas talvez

$\overline{1} \mathrm{O}$ contrato terapêutico se refere a um conjunto de normas estabelecidas anteriormente pela equipe e discutidas com os usuários a fim de que entendam e sigam as diretrizes de funcionamento da instituição. 
sejam necessárias, que certos controles estabelecidos funcionam de modo a favorecer a dependência do usuário à instituição. Essa questão, muitas vezes, é justificada pelos trabalhadores devido às atividades que o usuário deve realizar na instituição para que permaneça em abstinência mesmo alegando que o CAPSad atua na lógica da redução de danos, conforme preconiza a PAIUAD (Ministério da Saúde, 2003). No entanto, concordamos com Oliveira, Veronese e Palma (2009), quando mencionam que os dispositivos burocráticos, em muitos casos, subvertem a singularidade do sujeito - questão fundamental à efetividade do tratamento. Os autores afirmam que, quando os usuários fragilizados são expostos a estes dispositivos, o efeito pode ser uma "servidão mais que voluntária", que favorece a continuidade no processo de padecimento.

\section{Conclusão}

A partir deste estudo, pudemos notar que a lógica manicomial ainda se encontra presente nos serviços de saúde mental, fato percebido nas diversas práticas tutelares presentes no CAPSad pesquisado, como movimentos de "higienização de ruas", fortalecimento da dependência ao serviço e a supremacia da burocracia e dos controles em detrimento do cuidado.

Frente aos resultados encontrados, podemos nos perguntar se é possível estabelecer modos de acolhimento e cuidado sem o aprisionamento da vida e sem o assujeitamento dos usuários. Quais estratégias traçar para construir a autonomia dos usuários junto com eles?

Entendemos que, para evitar práticas de tutela e aprisionamento do outro, é preciso estar atento ao que as relações têm produzido: inventividade ou engessamento dos atos? Assim, é preciso rever freqüentemente se e quais estratégias biopolíticas estão operando na assistência ao usuário. Só desse modo será possível discutir os aspectos macro e micropolíticos que permeiam o processo de trabalho e as práticas de autonomia e cuidado no CAPSad.

Notamos ainda que, no que concerne ao aspecto macropolítico, é necessária a concretização de uma rede de atenção articulada, pois só assim se conseguirá junto ao usuário construir estratégias efetivas de autonomia, ou melhor, de não dependência, tanto das substâncias psicoativas quanto de um serviço.

\section{Referências}

Amarante, P. (1996). O homem e a serpente: Outras histórias para a loucura e a psiquiatria. Rio de Janeiro: Fiocruz.

Bardin, L. (2009). Análise de conteúdo. Lisboa: Edições 70.
Deleuze, G., \& Guattari, F. (1996). Mil Platôs: Capitalismo e esquizofrenia (Vol. 3). Rio de Janeiro: Ed. 34.

Franco, T. B. (2009). Prefácio. In T. B. Franco, C. S. Andrade, \& V. S. C. Ferreira (Orgs.), A produção subjetiva do cuidado: Cartografias da Estratégia Saúde da Família. São Paulo: Hucitec.

Franco, T. B., \& Merhy, E. E. (2006). O uso de ferramentas analisadoras para apoio ao planejamento dos serviços de saúde: O caso do serviço social do Hospital das Clínicas da UNICAMP (Campinas, SP). In E. E. Merhy, et al., O trabalho em saúde: olhando e experienciando o SUS no cotidiano. São Paulo: Hucitec.

Foucault, M. (1979). O nascimento da medicina social. In M. Foucault, Microfisica do Poder (R. Machado, Trad. e Org., 10a ed., p. XXI). Rio de Janeiro: Edições Graal.

Foucault, M. (1997). Il Faut Défendre la societe. Paris: Gallimard; Seuil.

Foucault, M. (1998). A ordem do discurso. Aula inangural no College de France, pronunciada em 2 de dezembro de 1970 (L. F. A. Sampaio, Trad.). São Paulo: Edições Loyola.

Foucault, M. (2008). Nascimento da Biopolítica. In Curso no Collège de France (1978-1979). São Paulo: Martins Fontes.

Lei n. 10.216 de 6 de abril de 2001. Dispõe sobre a proteção e os direitos das pessoas portadoras de transtornos mentais e redireciona o modelo assistencial em saúde mental. Diário Oficial da União.

Machado, R. (1979). Introdução: Por uma genealogia do poder. In M. Foucault, Microfisica do Poder (R. Machado, Trad. e Org., 10a ed., p. XXI). Rio de Janeiro: Edições Graal.

Merhy, E. E. (1999). O ato de governar as tensões constitutivas do agir em saúde como desafio permanente de algumas estratégias gerenciais. Ciência e Saúde Coletiva, Rio de Janeiro, 4(2), 305-314.

Merhy, E. E. (2002). Em busca do tempo perdido: a micropolítica do trabalho vivo em saúde. In E. E. Merhy, \& R. Onocko (Orgs.), Agir em saúde: Um desafio para o público (2a ed., pp. 71-112). São Paulo: Hucitec.

Ministério da Saúde. (2003). A política do Ministério da Saúde para a atenção integral a usuários de álcool e 
outras drogas. Brasília: Ministério da Saúde.

Oliveira, I. M. A., Veronese, L. G., \& Palma, C. M. S. (2009). A servidão mais que voluntária: Dispositivos burocráticos em instituição de saúde mental. Revista Mal-estar e Subjetividade, 9(4), 1343-1354.

Varanda, W., \& Adorno, R. C. F. (2004). Descartáveis urbanos: Discutindo a complexidade da população de rua e o desafio para políticas de saúde. Saúde e Sociedade, 13(1), 59-69.

Zambenedetti, G. (2009). Dispositivos de integração da rede assistencial em saúde mental: A experiência do serviço de saúde Dr. Cândido Ferreira. Saúde e Sociedade, 18(2), 334-345.

\section{Endereço para correspondência:}

Kallen Wandekoken

Endereço: Av. Antonio Gil Veloso, no 702, apt. 1002, Praia da Costa. Vila Velha/ES. CEP: 29101010.

E-mail:kallendw@gmail.com

\section{Endereço para correspondência:}

Bruna Quintanilha

Endereço: R. Santa Rita de Cássia, n 160, Bairro de Lurdes. Vitória/ES. CEP: 29042743.

E-mail: quintanilhabc@gmail.com

\section{Endereço para correspondência:}

Maristela Dalbello-Araujo

Endereço: Av. César Hilal, no 1181, apt. 1101, Praia do

Suá. Vitória/ES. CEP: 29052230.

E-mail: dalbello.araujo@gmail.com 